\title{
TOWARDS A MORE SUSTAINABLE FOOD SYSTEM IN BRIGHTON AND HOVE, UK
}

\author{
Adrian Ely, Elise Wach, Rachael Taylor, Ruth Segal and \\ Rachael Durrant
}

\section{Introduction}

Brighton and Hove is a city on the South coast of the United Kingdom (UK) with a population of approximately 273,369 (United Kingdom Census, 2011). The city is surrounded by a highly biodiverse and productive chalk reef system to the South and endangered chalk downland habitats to the North. Two recent events have increased attention towards biodiversity conservation and wider sustainability issues in the area (including agricultural land). First, in April 2011 the South Downs National Park became operational (South Downs National Park Authority 2012), bringing a shift in responsibility for planning to the wider area. About $40 \%$ of the city sits within the boundaries of the national park. Second, in June 2014 Brighton and Lewes Downs (including the city of Brighton and Hove and the county town of Lewes) became the first completely new World Biosphere site established in the UK for almost 40 years. The University of Sussex is a member of the Brighton and Lewes Downs Biosphere Partnership, and research undertaken as part of these initiatives informed the proposed study.

Beyond this, the hub drew significantly upon the work of the Brighton and Hove Food Partnership (BHFP), a local multi-stakeholder platform that aims to create a sustainable, healthy and fair food system for the city. BHFP's 2012 strategy "Spade to Spoon: Digging Deeper" (BHFP 2012) stated:

- " $26 \%$ of the city's ecological footprint (the amount of land and resources we use) relates to food (also known as the city's 'foodprint')".

- "To produce enough food to feed the population of Brighton \& Hove we need approximately 70,000 hectares of productive agricultural land". 
- $\quad$ "Each year the food produced on that land requires approximately 750,000 barrels of oil and almost 625 million tonnes of fresh water. In all, this generates an estimated half-a million tonnes of greenhouse gases".

- "We have about half the number of recommended allotment plots. The total number of plots at the beginning of 2011 was 2,795 , which is 10.9 per 1,000 people. There are 1,612 residents on the waiting list".

- "The infrastructure supporting the local food supply chain is not as advanced as in some regions, which have developed local distribution centres, established cooperative wholesalers and invested in local processing (e.g. mills or abattoirs)".

- "Over recent years, the number of Brighton \& Hove residents employed in agriculture has fallen by $40 \%$ (the average UK drop is closer to $20 \%$ )".

The UK hub's work grew out a well-documented and well-researched understanding of the dominant agri-food pathway in the UK - one characterised by market-driven consolidation of both production and supply chains leading to ever larger-scale (more mechanised, input-intensive and less local) production and serving national and international supermarket chains. It also built upon several years of research, conducted by colleagues within the University of Sussex, which engaged with alternative agri-food pathways in Brighton and Hove and the surrounding area. This included research on:

- Studies of the history of organic farming in the UK (Smith 2006) looking at the influence of the niche on the incumbent regime (the dominant pathway).

- 'Grassroots innovation niches' such as community growing (White and Stirling 2013), which studied the role of community-organised, not-for-profit urban agriculture (within the city itself).

- The role of civil society organisations in food system transitions (Durrant 2014) - a doctoral project that had examined civil society networks beyond the city, including larger community-supported agriculture initiatives such as Tablehurst and Plaw Hatch Farms.

- A study of Seedy Sunday - the UK's largest and longest-running seed swap, which takes place in Brighton every February (Balázs et al. 2016).

- 'ARTS' (Accelerating and Rescaling Transitions to Sustainability) - an EU project in which the role of civil society and policy action in Brighton and Hove had been examined alongside similar phenomena across other European cities (Durrant et al. 2018).

As such, several of the research team had engaged with these issues in the preceding years.

Findings and relationships from this work fed into a co-design workshop in January 2015, at which researchers gathered together with local and national civil society organisations and commercial and non-commercial growers. While encouraging, the contribution of the urban agriculture pathway (White and 
Stirling 2013) to serving the city's food needs was seen by participants at the workshop as limited in a context of insufficient access to land and a range of other constraints. Therefore, participants decided that the study should build upon the current understanding of how these pathways - i.e. the urban agriculture pathway and the dominant agri-food pathway - interacted, focussing on what was termed the "missing middle". This was the current and potential contribution of commercial scale farms that are slightly larger than the community gardens and allotments in the city (which receive government support) but smaller than farms which receive significant amounts of government subsidies. As they do not qualify for community or grant support, they were perceived as being at risk of economic collapse in the current economic context, particularly given high rates of attrition among these types of farms at a UK level (Willis 2017, Winter et al. 2016). On the other hand, their size and positionality could also enable them to engage in experimentation and innovation towards sustainable food systems (not only in production techniques but also in supply chain experimentation).

While it was clear that $65 \%$ of holdings in the South Downs National Park are less than 100Ha in size (South Downs National Park Authority 2012), the extent to which these and other farms local to Brighton and Hove served the city, and the sustainability of their operations, was unclear. Using interviews and desk research, the study proposed to collect examples of good practice, integrating sustainable production methods with local medium-sized supply chains (e.g. serving small, specialist wholefood supermarkets in Brighton and Hove) in the hope of pointing to lessons for other parts of the country. At the same time, the research proposed to investigate the constraints facing medium-sized farmers in serving the city. Reflecting the interest of the Argentinean team's focus (see Chapter 8) and the local interest in seed saving and exchange (exemplified by Seedy Sunday), seed was of particular interest to the research team.

The boundaries adopted at the outset of the project, therefore, were the food system in the city of Brighton and Hove, and in particular the production of food in the South Downs National Park and Brighton and Lewes Downs Biosphere Region (see map below). The "problem space" was defined as: "The food system in Brighton and Hove is unsustainable because of limitations to local food supply and environmentally damaging production and consumption practices". The transformation required to overcome it was seen as "increased localisation of supply and encouraging innovation for sustainable food production and consumption".

The baseline survey helped to map the situation (according to the research team) at the outset of the project. The existence of various box schemes and supermarkets that offered local produce to a minority of consumers suggested some recognition of the problem space among the general public. In comparison, the problem was recognised as important by civil society and academic groups. In particular, the problem was widely recognised among those studying environmental sustainability and food policy across the UK as well as locally (e.g. across Brighton-Sussex University Food Network - a locally run knowledge centre on 
the theme of food). In terms of mobilisation, there was seen to be a powerful civil society movement at national and international levels, focussing on local, sustainable food production. In Brighton and Hove there was already some mobilisation, but not necessarily co-ordinated across the city region (beyond the work of BHFP, which primarily focussed within the city). The private sector was seen to have responded in a limited way, with a limited number of restaurants and retailers in the city that prioritised locally produced (or environmentally sustainably produced) food. Some farmers had innovated to develop novel retail approaches to serve this niche (e.g. farmers' markets, box schemes). In terms of governance, at the national level, the UK government offered very limited, if any, support for localised food networks prioritising environmental and social sustainability, although some support came from national charities (and the national lottery). At the local level, Brighton and Hove City Council recognised the need to localise food production and were strong partners within BHFP. Through the City Food Strategy (BHFP 2012) they aimed to work with local communities on food projects for health, rehabilitation and other social goals, though their focus has been more on the consumption side than on production, with the exception of community gardens and allotments.

Although there were no major conflicts associated with the problem space, the baseline survey highlighted some general political issues about inequality and access to land. A more specific tension emerged from the observation that consumers usually demanded cheap, diverse (but often unsustainable) food supplies, which can often be supplied more efficiently by vertically integrated supermarket chains than by local suppliers and retailers.

\section{Theory, research and action}

The hub adopted a theoretically informed approach combining empirical research and stakeholder engagement. The pathways approach (Leach et al 2010) provided the primary theoretical underpinning of the work, with policy actors as the key audience and a strategic approach to communications envisaged as a way to raise awareness and bring about changes in knowledge, attitudes and skills.

Theories of change developed as the project evolved. The co-design workshop - which was undertaken in January 2015, at a time when funding for the research was yet to be secured - was supplemented by a Participatory Impact Pathways Analysis (PIPA) exercise involving Adrian Ely and Nathan Oxley (STEPS Centre Communications Manager) at the inception workshop in April 2016. As a route to developing an instrumental theory of change for the project, the PIPA exercise produced a network map identifying research organisations, local and national NGOs, government organisations, private sector enterprises (including farmers, digital sales platforms, retailers and restaurants) and local media as key strategic partners. Brighton and Hove Food Partnership was recognised as a powerful convenor, and consumers were identified as the most powerful group in terms of enabling transformation. All actors other than large 
farmers, consumers and national media were seen as normatively aligned with the research team (i.e. likely to be welcoming of the transformation being envisaged). A continuous process of research, iterative communication and reflection with these stakeholders was proposed as a way of understanding how policy did, and could, support transformative pathways involving sustainable agriculture in the "missing middle".

Our more general conceptual theory of transformation was only codified later, at the T-Lab training and reflection workshop in Dundee in August 2017, in the following terms: "Transformation is influenced by changing cognitive, affective and political economic drivers that work across individuals, groups and systems". Concepts of particular relevance to this theory of transformation were identified, including the 'pathways' approach (Leach et al. 2010), 'politics of green transformations' (Scoones et al. 2015), 'governance of sustainable socio-technical transitions' (Smith, Stirling and Berkhout 2005), and 'transformative pathways' in particular (Ely and Marin 2016).

The research involved two stages. Prior to the first T-Lab workshop we conducted interviews with small- to medium-sized farms and gardens, policymakers and retailers, and surveyed attendees of Seedy Sunday 2017. Whereas the interviews were envisaged as a core part of the study design, the survey was an additional research activity commissioned by the organisers of Seedy Sunday. Following the first T-Lab workshop we conducted desk research, supplemented by further interviews. During this stage we focussed less on researching the context in Brighton and Hove, and more on drawing lessons from other localities. Our instrumental theory of change thus moved towards one of 'seeding ideas' and knowledge brokering.

Our ambitions for action rested on engagement of different groups of stakeholders through T-Lab workshops. The engagement methods selected for use during the T-Lab 1 workshop were intended to bring together diverse stakeholders who may not have engaged with one another on a regular basis. The specific methods planned for the T-Lab were a roundtable session taking feedback from stakeholders on the research findings; an adapted Evaluation $\mathrm{H}$ exercise to elicit a broad range of divergent perspectives on the ease of supplying sustainably produced food to Brighton and Hove (see below on Evaluation $\mathrm{H}$ ); and an exercise mapping positive and negative factors, building on discussions from the Evaluation $\mathrm{H}$ (and moving towards the identification of positive actions and social innovations). The methods used took an 'open space' approach to allow themes, priorities and ideas to emerge from discussions, thus accommodating a pathways perspective of plurality and diversity. After the T-Lab 1 workshop we hoped to catalyse further action by maintaining contact and networking through additional workshops and events, and by publishing a briefing at the end of the project that pointed to specific opportunities for policy innovations (related to a revision of the Whole Estate Plan (WEP) for the Downland Estate - see Box 5.1). Overlapping with and informing this second stage were two further projects associated with the Sussex Sustainability Research Programme (see below). 


\section{BOX 5.1 THE DOWNLAND ESTATE}

The Downland Estate, which now includes over 4,000 hectares of farmland, has been owned and commercially managed by Brighton and Hove City Council since 1913. The land was initially acquired to protect the city's drinking water supply and control development; however, a range of more diverse aims and objectives were first formalised in 2005 (codified in the Downland Initiative Feasibility Study - see Smiths Gore and University of Reading 2006). These include income and capital provision as well as the facilitation of conservation, education, public access and agriculture. During 2018-2019, the Council began to revise the Whole Estate Plan (WEP) for the Downland Estate, in order to provide a coherent strategy for managing this portion of the South Downs National Park.

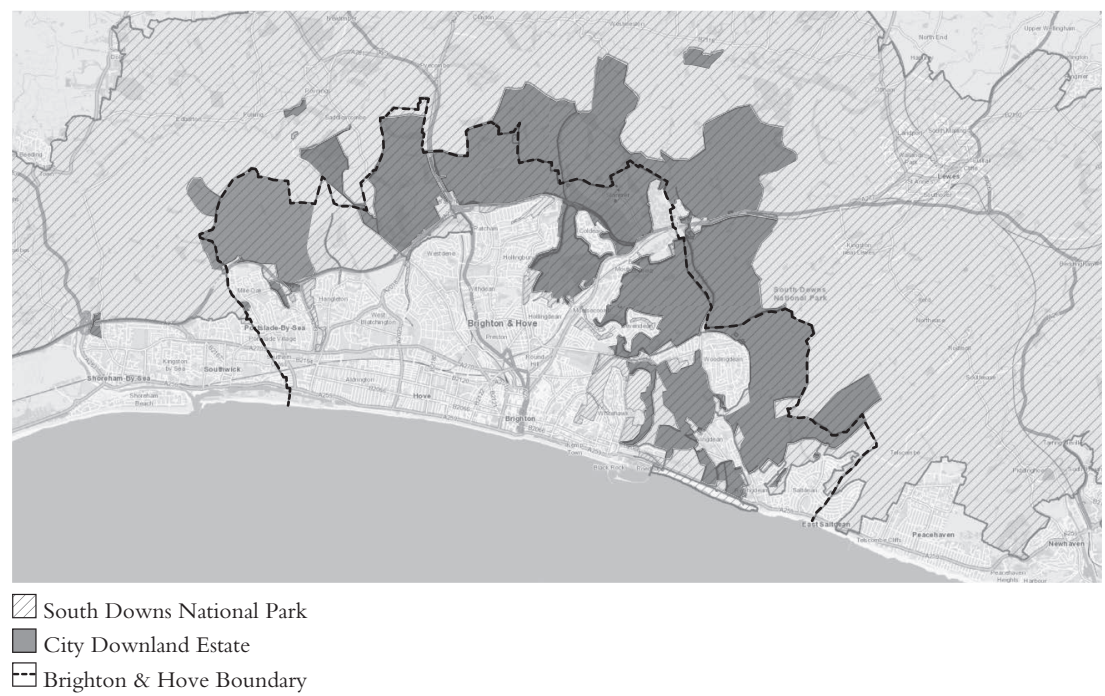

FIGURE 5.1 Map showing the City Downland Estate in relation to Brighton and Hove and the South Downs National Park.

Unlike other hubs (e.g. Argentina) the UK hub moved from engaging with a more aligned to a less aligned group of stakeholders as it progressed. We also found that we engaged successively with increasingly powerful groups. This is illustrated pseudo-quantitatively in Table 5.1, which draws upon the highly subjective assessments of power and alignment produced at each convening event.

As a stakeholder without a direct economic stake in the way that land is managed (both within the city limits and across the South Downs National Park and Brighton and Lewes Downs Biosphere Region including the Downland Estate), 
TABLE 5.1 Average alignment and power of actors/individuals as estimated from PIPA exercise and first and second T-Lab workshop reports

\begin{tabular}{lll}
\hline Event & Average "power" & Average "alignment" \\
\hline Co-design workshop & Not recorded & Not recorded \\
Initial network mapping (PIPA) at inception & 1.39 & 0.96 \\
$\quad$ workshop, April 2016 & 1.12 & 1.0 \\
T-Lab workshop 1, December 2016 & 1.69 & 0.73 \\
T-Lab workshop 2, July 2018 & & \\
\hline
\end{tabular}

Average "power" estimated on a scale of $0-5(0=$ envisaged to have no influence, $5=$ the most powerful actors). Average "alignment" estimated on a scale of -1 to $+1(-1=$ expected to be negative or resistant, $0=$ expected to be uninterested; awareness/persuasion needed, $+1=$ expected to be positive or welcoming with regard to transformation).

or any specific political ties, we were able to convene multi-stakeholder groups over numerous occasions during the life of the project. This is significant and is partly a result of the reputation of the University, which had been built up over several decades, as well as (more recently) the Brighton and Sussex Universities Food Network (BSUFN). This apparent legitimacy of researchers both as convenors (of aligned and non-aligned groups) and as a source of authoritative knowledge called for a careful approach. We therefore entered the T-Lab events without our own predefined goals, attempting to foster a process through which goals would emerge on the basis of the shared discussions (resulting in more shared ownership of the outcomes). We also needed to be cognisant of our limitations as mediators (Ely and Marin 2017), and to be constantly aware of the limitations on our resources. The UK hub had comparatively fewer resources than the other hubs, and - recognising this - we were not able to position ourselves as key agents of transformation. It was therefore challenging to convene events with a transformative agenda without inappropriately raising expectations among other stakeholders.

Although they did not lead to any concrete initiatives, the T-Lab events provided a forum where new ideas could be discussed and new connections were made (as evidenced by emails received after the events), which potentially forms the basis for policy advocacy going forward. The events also played a role in establishing and strengthening links between researchers (across disciplines at the Universities of Sussex and Brighton) and other groups (Council, civil society, private sector), some of which continue to grow in areas that are related to, but not directly the focus of, our project. At the same time, they built on earlier research and relationships, just as the project has done since its outset in 2015.

In addition to the T-Lab events, impact-oriented evidence, taking the form of provocative discussion papers and talks, was presented to increasingly powerful (and non-aligned) audiences. This may not have led to a direction-change in knowledge, attitudes or skills, but provided an impetus for alliance-building, debate and challenge. 
74 Adrian Ely et al.

Taken overall, this way of working is strongly aligned with Ely and Marin's 'transformative pathways' approach, developed during the early stages of this project, which envisages the role of transdisciplinary research as follows:

In seeking transformative pathways, in which directions are potentially unknown (or at least uncertain) but normative commitments are shared, the role of transdisciplinary research becomes one of fostering, supporting or reconfiguring such coalitions and alliances, and working with them to co-construct and mobilise impact-oriented evidence.

(Ely and Marin 2017)

This remained the approach through both of the T-Lab workshops described below.

\section{Key moments in the T-Lab process}

The research and T-Labs proceeded through various stages. The two T-Lab workshops described here were punctuation marks in a longer, ongoing process of research and engagement, advocacy and action (see below).

Following the co-design workshop, the team recognised that they needed to better-understand challenges facing farmers, both in their selection of technologies and management practices for food production, and for their marketing strategies. These insights would be important not only for us, but also for policy-makers and others in the supply chain who are keen to support farmer innovation. With this aim in mind, the research team built a database of local agro-ecological farms within $50 \mathrm{~km}$ of Brighton and Hove, primarily less than $20 \mathrm{Ha}$ in size (similar to that used by Laughton et al. 2017). A decision was made to focus on non-animal agriculture on the basis of better health outcomes for consumers and greater efficiency of land and resource use, as compared to animal

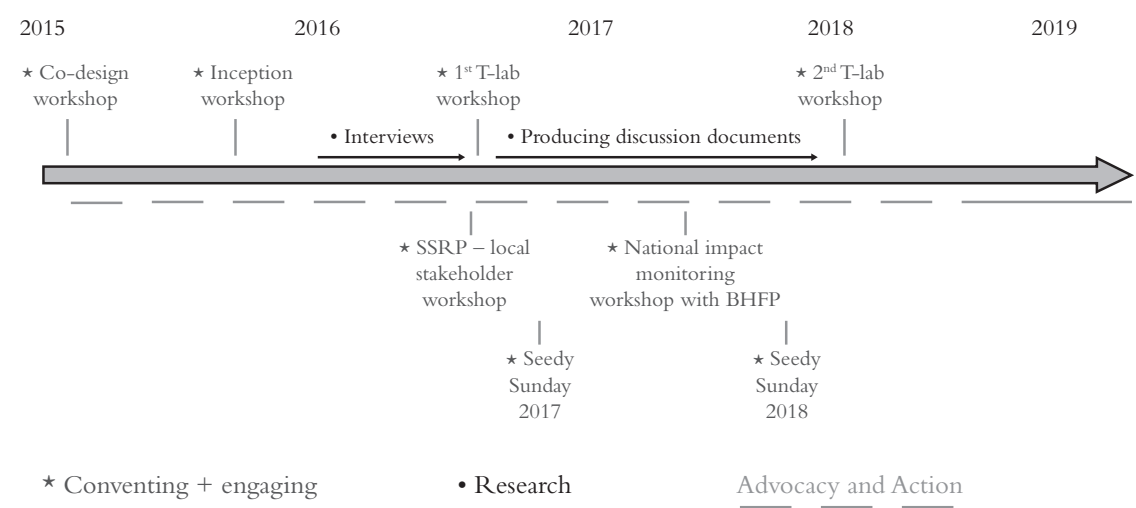

FIGURE 5.2 Key moments in the UK T-Lab. 
agriculture. This nevertheless excluded the majority of farms on the downland surrounding the city, which focus on sheep and cattle (although a later project was able to explore the dimensions of animal agriculture - see "Delivering food security and biodiversity conservation through rewilding and community agriculture" below).

Primarily through semi-structured interviews, we gained significant insights into the constraints facing farmers and the challenges for local, sustainable agrifood systems (covering issues such as crop types, technologies and practices, experiences of policy support and marketing strategies). There was very limited policy support, with only one farm in our sample receiving the single farm payment (under the EU Common Agricultural Policy). Some additional findings problematised the initial framing of the research and led us to reflect upon the terminology we had adopted:

- We identified a general questioning of the notion of 'sustainable', with varying emphases and priorities - environmental, social and economic - adopted by different farmers.

- There were also differing definitions of 'local' (varying from the nearby village - closer than Brighton and Hove - to national markets).

\section{T-Lab workshop 1}

These findings were presented to a workshop in December 2016, which comprised two parts: one which focussed on the challenge of connecting research, policy and action for food systems in Brighton and Hove more generally, and the second which focussed on the transformations project specifically. Running the two events on sequential days enabled us to situate our own interests within the broader 'system' and to be aware of some of the multitude of potentially transformative initiatives (and research projects) already underway. These two events were held in the 'space maker space' - a room created for local groups to meet, especially to visualise the future of the city.

The first workshop broadened out academic participation to include an interdisciplinary group of researchers from across the University of Sussex who were proposing to conduct research on local agri-food systems as part of the Sussex Sustainability Research Programme (SSRP) - a recently established fund that the University of Sussex had set up to foster collaboration across campus. In addition to presenting highlights from the research findings, four candidate projects were presented, two of which involved authors Adrian Ely and Rachael Durrant and eventually received funding:

- "People, pollinators and pesticides in peri-urban farming" - a citizenscience project that investigated how food was being grown in urban and peri-urban areas (primarily allotments), including how growers control for 


\section{Adrian Ely et al.}

insect pests, with a view to better-understanding the role of different kinds of pollinators in the urban context.

- "Delivering food security and biodiversity conservation through rewilding and community agriculture?" - an interdisciplinary project that examined the ecological and social dimensions of a range of approaches to land management involving large herbivores in the South East of England, including agro-ecological farming, conservation grazing and re-wilding.

These two projects provided further opportunities for the local hub project work to be interpreted within the wider context of Brighton and Hove's food system. They continued until their conclusion at around the same time as the end of the formal 'Pathways' transformative knowledge network (TKN) project.

The morning's facilitated discussions aimed to understand how transdisciplinary research such as ours, or such as that associated with SSRP, could better effect change. During this discussion, one participant (a researcher) said that they did not think more research was needed, proposing that it was rather action that was required. They questioned whether research outputs from this, and other, projects could sufficiently effect change to bring about a more sustainable food system for Brighton and Hove. Discussion around this issue raised some tensions between research, action-based research such as this project, and practitioners who only engage in action.

The research findings were reported in more detail to a similar (but augmented) group of stakeholders the following morning (the main element of our first T-Lab workshop). In order to deliver this in an engaging way we employed an external professional facilitator, who used the 'Evaluation H' method (see below) to explore the question "How easy is it to supply sustainably-produced food to the city?" Following on from this, a mapping exercise built on the discussions of positive and negative factors, with participants split into two groups, one for positive (encouraging) factors and one for negative (limiting). The groups were initially invited to add to the factors that had been identified so far, their attention being directed towards 'neglected' factors. After that, participants were invited to consider the various factors and how they were addressed (both in terms of strengthening them or helping to overcome them) by existing policies, systems and research, and then asked to note down changes in the above (new policies, system changes or research) that could further contribute to making it easier for small and medium-sized food producers to supply sustainably produced food into Brighton and Hove.

Up until this stage, we had been planning to help build consensus across different views, within an area where there was a plurality of perspectives and contestation about priorities (e.g. the actual and potential role of locally produced food). Ideally, we hoped to develop ideas for social innovations that might drive transformation. What we actually drew from the workshop was a renewed and revised agenda for research, building on that which emerged from the co-design workshop, but with a greater emphasis on the two challenges that participants 
(especially producers) prioritised. These were access to land for local and ecological food production and coordination of markets and logistics/distribution systems between producers, retailers and consumers. The plan to produce two briefing papers, one on issues associated with access to land and the other on market coordination strategies, is what emerged, largely on the basis of a new network map/PIPA produced by the research team on the afternoon of the second day. In the interim, the Council had announced plans to sell currently publicly owned, tenancy land into private ownership, which led to some public mobilisation against the proposals (Vowles 2016). Partly as a result of this, the 'access to land' paper was subsequently reframed to address potentials for a more local and sustainable food supply, delivered through agro-ecological food production on Brighton and Hove's Downland Estate, which became the focus of our second T-Lab workshop.

Shortly after the workshop, Adrian Ely was invited to join an expert panel for the City Food Strategy. He also worked with Brighton and Hove Food Partnership to organise a national workshop (in September 2017) at the University of Sussex that helped to inform a plan to measure the impact of taking such a citywide perspective on food.

\section{T-Lab workshop 2}

The second T-Lab workshop involved a total of 23 people and used less formal approaches than the H-evaluation used previously. The event was held in a rented space in a building often used by civil society organisations working on food in the centre of Brighton. After an ice-breaker, the research team went on to give a short presentation on the preliminary findings of the research into the potential for agro-ecological food production on the Downland Estate. This provoked a lot of discussion. There was some criticism of the presentation of one of the statistics (based on research by another Sussex colleague) as "sensationalist" and we were also critiqued for the small number of tenant farmers that had been interviewed. However, these critiques mainly led to productive debate and the tensions that were raised did not lead to any particular point of view dominating the discussion.

Next, facilitated small group discussions (involving a diversity of actors in each) were used to map the following (with regard to the role of the Downland Estate in contributing to a sustainable food system for Brighton and Hove):

- Negative/limiting factors

- Positive/encouraging factors

- New ideas.

Many of the issues raised in the first T-Lab workshop (including logistics and marketing, training needs for farmers) were repeated spontaneously on different tables at the second T-Lab, which is encouraging (to the extent that we are 
identifying widely viewed challenges and potential solutions). Discussion of new ideas led to recommendations (generally shared) around the need for a democratic process to identify the 'purpose' of the Downland Estate, the potential value of a survey of soils and other characteristics of the estate (to aid in zoning decisions), and the idea of a research and innovation hub to support transformations to sustainability in the city/biosphere region. The role of the Downland Estate was a politically controversial issue, and there was a desire among some participants to get this on the Council's agenda in advance of the next local elections in May 2019. We failed to do this, primarily because of lack of resources and a political environment of austerity in which cuts to public services and issues of poverty and homelessness became core election issues. However, the issue later became the focus of a Council consultation.

\section{Lessons from the entire T-Lab process}

Through these key moments in the T-Lab process, we focussed down on more and more specific priorities associated with the transformation underway - e.g. identifying small farmers in the co-design workshop; access to land as one of the priorities in the first T-Lab workshop; and the Downland Estate as a focus for action in the second - as directed by a network of academic and non-academic participants that broadened out to include increasingly divergent perspectives. As such, a transdisciplinary approach was certainly used, even though we did not work directly with non-academic partners in conducting the research. Such an approach to co-production was difficult as it required regular meetings, sharing information, strategic discussions and going to great lengths to co-ordinate diaries. In particular, where participants were not generally aligned with our view of the transformations required (and may have been among the more powerful), this was even more burdensome. Beyond that, the skills possessed by team members, and the kinds of research that we aspired to do, have not always met the expectations of our participants in terms of what is 'required' or 'needed'. For example, where some have looked to us to provide evaluations we have instead provided input to monitoring and evaluation plans. Others have placed a premium on quantitative knowledge based in the natural sciences, rather than the kind of work that we are more used to undertaking, thereby raising questions about our possible contribution.

The recommendations from the second T-Lab workshop could be seen as aspects of 'designing innovation' (one of the overall aims of a T-Lab process - see Chapter 4). However we were at the very early stages and had not yet reached the stage of 'prototyping'.

\section{Impact, outcomes and pathways}

The project is best seen within the context of the broader efforts of researchers at the STEPS Centre, and the University of Sussex. By working together over the 
timeframe of the project, they have provided evidence to support transformation towards enhanced sustainability in the local agri-food system. At the same time, this is difficult to measure, characterise or attribute as a result of the diffuse nature of this work. Whereas the evidence collected from project surveys provides a picture of change, it does not provide proof of change that is attributable to the project work itself, except in some cases where there is at least circumstantial (and some documentary) evidence for a contribution to these changes. The kinds of changes documented by the project include changes in relationships and networks, policies and practices, as well as knowledge, attitudes and skills, among the various stakeholders, assessed (subjectively) on the basis of the baseline survey and the final survey.

With respect to changes among the research community at the University of Sussex, the SSRP has supported collaborations across the natural and social sciences, including the two projects listed above that benefited from participation in our first T-Lab workshop. It could also be argued that the project work, combined with SSRP initiatives, has contributed to better linkages between research, policy and action. As evidence for this, the research team received approaches for collaboration from actors previously unknown to us (private sector and civil society). Members of the project team also made efforts to collaborate with colleagues at the University of Brighton (e.g. through joint funding applications) but have to date not been as successful. Additionally, we can observe changes in our knowledge and understanding of the actors involved in the problem space. In looking back at the original PIPA network that was constructed at the inception workshop, it is clear that our knowledge has increased considerably since then. In terms of our mapping of relevant actors at a local-to-regional level, we have added the land agents who serve the local authority and several statutory bodies including the South Downs National Park Authority, Natural England and Sussex Wildlife Trusts; at a national level we have added civil society groups such as the Sustainable Food Cities Network, Ecological Land Cooperative and Food Research Collaboration. Indeed, initiating, enhancing and maintaining alliances across the various stakeholders above have perhaps been our greatest contribution to change.

In terms of changes among the general public, the mobilisation against proposed changes to Council-owned farmland in 2016 was notable. These proposals were to a) sell currently publicly owned, tenancy land into private ownership, and b) develop a large area of the Downland Estate that is designated as a Nature Reserve into housing in 2018-2019. In terms of changes among civil society groups, strengthened links between the University, the Council-led 'Brighton and Lewes Downs Biosphere' and the Brighton and Hove Food Partnership have contributed to discussions about links between local production and consumption in the City Food Strategy (BHFP 2018, aim 4, including 4.1.5). In particular, Brighton and Hove Food Partnership developed a longer-term partnership with the project team as one of us became involved in the design and implementation of the city food strategy (BHFP 2018). Moreover, in terms of the social enterprise 
sector, retail and restaurant niches focussing on local and sustainable food also seem to have strengthened (although this is difficult to evidence), while a private online platform facilitating local producer-consumer supply chains (Food Assembly) was first established in 2015, and then subsequently shut down in 2018 (Farm Drop 2018). We were informed by one of the participants at our second T-Lab workshop that a local farmer had decided to dedicate part of his farm to diverse agro-ecological production for supply within a 15 mile radius, inspired by the ideas we were trying to push.

In terms of politics and governance, a number of local protests (mentioned above) took place during the course of the project, which led the City Council to run a committee-based enquiry into the Downland Estate. Since then, a wider recognition of the need to think strategically about the land around Brighton and Hove has grown among key decision-makers (primarily the City Council and the South Downs National Park Authority), which manifested in the development of a new Whole Estate Plan for the City Downland Estate (see Box 5.1). The Council adopted a progressive, participatory and consultative approach to this planning process from 2020 onwards (in line with the recommendations from our second T-Lab workshop), which aimed to "set out a vision for how our downland could be managed over the next 100 years" (BHCC 2020).

At the national level, the austerity policies of the Conservative government (2016 to the end of the project) led public policy to seek new sources of funding in order to address budget deficits (e.g. leading to the proposals to sell public land). The Brexit referendum vote in 2016 also had an impact on government at local levels and an overwhelming effect on the changes at the national level. The potential room for manoeuvre provided by Brexit (in terms of the UK setting its own policy, following the Common Agricultural Policy) precipitated a number of policy consultations and long-term strategies relating to environment and food being put in place. This, in turn, created uncertainty among some groups (especially farmers, according to evidence from our T-Lab workshops) as there was little clarity on the details and timeline of implementation.

In terms of observing shifts in the alignment of actors, some of those who were thought to be resistant to change were - by the end of the project - more open than expected. It is not clear whether this is a result of our misunderstanding at the outset, or a shift in their knowledge, attitudes and skills. For example, some farmers at the second T-Lab workshop were open to some kind of re-allocation of land (e.g. sub-letting) to agro-ecological farmers on the basis that it contributed to sustainable food systems (although the economic aspects of this were not clarified). Some robust arguments were put forward (e.g. by agro-ecological farmers) that it was possible to grow vegetables on what had traditionally been thought of as 'marginal' land, and some of the participants, including conventional farmers and policy-makers, appeared to accept these arguments. In addition, some of the actors who had been expected to be resistant (e.g. large conventional arable producers) seemed to accept the arguments put forward by the project team (i.e. that there was significant potential for agro-ecological 
farming to contribute to the city's food supply, including addressing food poverty) and learnt from the contributions of one of the agro-ecological producers and other commercial ecological farmers in the area.

\section{Research methods}

We used a combination of web-based research, semi-structured interviews and strategic engagement. During T-Lab workshops, our external facilitator adapted the "Evaluation H" method as described in Box 5.2 (see also STEPS Centre 2017).

\section{BOX 5.2 EVALUATION H}

\section{Background}

Evaluation $\mathrm{H}$ derives from the $\mathrm{H}$-form/'Rugby Post form' Evaluation method developed by Andy Inglis in 1997 to assist local people in Somalia in monitoring and evaluation (Guy and Inglis 1999).

Beyond a standard 'continuum' or 'line' method that allows participants to position themselves (or their perspectives) on a line of possibilities, Evaluation $\mathrm{H}$ has an additional dimension. It encourages participants to directly and specifically identify the positive or negative factors that influence their position on the line. They can be clustered, and, through a facilitated process, used as a focus for discussing what needs to happen to build upon and strengthen positive factors, or to overcome or address negative factors, in order to support an overall objective.

\section{What's involved?}

The facilitator of the exercise poses a question to the group, which is related to the issue being explored, with the question written at the top of a wall, table or large sheet of paper (the work surface). A horizontal line is drawn across the centre of the work surface, providing a continuum for opinions, e.g. good to bad, easy to difficult, important to not important. Participants are each given sticky notes and pens, and asked to consider their response to the question posed by the facilitator and where on the continuum reflects/ represents their response. Participants are also asked to write the factors (positive and negative), which influence why their response falls at the position on the continuum they have identified. Once all participants have added their sticky notes to the work surface, each of the responses is discussed with every participant having the opportunity to explain their perspective. The factors identified can be positive or negative, and are usually attached to vertical lines at either end of the continuum (hence the ' $\mathrm{H}$ ' or rugby post 
name). Ideally the factors are then clustered to identify any common themes that arise and then each distinct cluster can be analysed, i.e. what needs to happen to overcome or address this negative factor, or to build upon and strengthen this positive factor.

\section{Broadening out and opening up}

The Evaluation $\mathrm{H}$ method is useful for identifying different perspectives along a continuum. As long as a broad range of perspectives are present and feel free to contribute, this is effective at 'broadening out' discussions around an issue. Ideally, the method brings plural perspectives on the issue to an equal status but can also highlight 'outliers' or more marginal views. The dialogue which explores participant's responses then opens up in an attempt to address the plurality of framings. As such, this method can be particularly effective if participants represent different sectors, backgrounds, or types of involvement in the issue being explored, particularly if these different stakeholders do not interact often. Discussion of each participant's responses allows each diverse perspective to be explored, bringing different framings of issues to the surface and illuminating multiple diverse ideas, opportunities, strategies or recommendations. Dialogue emerging from discussion can also help to address dynamics between perspectives, including tensions, commonalities, gaps or opportunities.

\section{Fits and limits}

A strength of the Evaluation $\mathrm{H}$ method is that it can engage a range of stakeholders, sectors and backgrounds on an even plane, where each participant is held as equal and their responses given equal importance (although this is dependent on appropriate facilitation). This allows each participant to give their perspective in their response to the question without feeling judged or marginalised by other participants. Conversely, a potential weakness of the method is that participants may not feel comfortable, willing or able to give their perspective or reflect on their response with others (especially if the exercise is poorly facilitated).

\section{Re-framing the project - problems and priorities}

Our theory of change did not explicitly talk about re-framing. However, within a general pathways approach it sought to illuminate and highlight different framings and - through research and engagement activities - to bridge between them. Thus, through bringing in new evidence and ideas, it contributed to various reframing processes (discussed further in Chapter 11). 
The framing of the problem space that was initially chosen did not change fundamentally, but evolved throughout the course of the project. This framing was worded in terms of the "unsustainability of the food system in Brighton and Hove, because of limitations to local food supply and environmentally damaging production and consumption practices". However, during the course of the three years, the initial focus on localisation of supply and innovation for sustainable food production and consumption gave way to more focussed work in the area of market linkage strategies, access to land and land use. In line with local discussions and mobilisation on these issues, this led to a further focussing of attention onto the Downland Estate. Hence, whereas our first project briefing on 'Market Co-ordination' (Taylor 2018) addressed linkages between urban food consumers, local food producers and the urban hinterland with reference to other UK cities, our second project briefing on 'Land' (Wach and Ely 2018) addressed the issues of access to land and land use in and around Brighton and Hove, and our third and final project briefing on the City Council's 'Downland Estate' (STEPS Centre 2019) was an overt attempt to re-frame local debates about the Whole Estate Plan. The project's increasing topical focus was therefore complemented by an increasingly situated framing of the research.

In terms of how this might have led other stakeholders to question established framings and adopt different or altered framings, our approach was slightly different at each stage, with different project outputs. The approach taken in the writing of the first output (Taylor 2018) was to present evidence from other UK cities where market linkages had been reconfigured as a result of public policy or civil society action, as a way to demonstrate what is possible. The second output (Wach and Ely 2018) used a similar approach in an attempt to reframe the widely held notion that the potential of the downland surrounding Brighton and Hove was limited - by geomorphological constraints - to landscape provision, livestock production and (to some extent) arable farming. It did this by using the case of a local community-supported agriculture (CSA) scheme to illustrate its potential for fresh vegetable production. However, it also attempted to reframe this area, which encompasses the Downland Estate, as part of the city (due to it being included in the City Food Strategy Action Plan and its ownership by the City Council). The third output - the report from the second T-Lab workshop - took a different approach, aiming to persuade decision-makers and other stakeholders to move beyond seeing the Downland Estate primarily as a source of revenue for the City Council - and towards a broader view of its value. Rather than using research to highlight the potential of the Estate by reference to examples, the briefing called for the City Council to consider adopting a more democratic/ participatory process to identify the 'purpose' of the Downland Estate.

Our attempts, and those of others, to call into question the predominant framings of the potential of the land surrounding Brighton and Hove, as well as the value and "purpose" of the Council-owned Downland Estate, seems to have had some impact - though this is hard to evidence directly. The potential is that reframing the area in this way could lead to more attention from local authorities, 
greater feelings of ownership or engagement by other local organisations or citizens, and a greater appreciation of the role of local farmers for environmental management practices (e.g. those who use less fertilisers, with resultant benefits for water quality). Our suggestion for a broader framing of this area of land revolved around a recognition of its multi-functionality and the ecosystem services it provides, including local food supply, as well as public access and education (Wach and Ely 2018, STEPS Centre 2018). Some of the participants at the second T-Lab may have started to adopt these broader framings - partly as a result of us convening the meeting, engaging them over these issues, and highlighting the history of the 'Downland Initiative' Feasibility Study (Smiths Gore and University of Reading 2006). However, this was happening alongside financial constraints on the City Council, making it more difficult to translate intention into action.

On reflection, by adopting the "seeding ideas" approach (Ely et al. 2017) acting as knowledge brokers and giving examples from elsewhere - we were able to shake up 'received wisdoms', provide examples from other local authorities that differed from the local approach and also adopt different assumptions to those implicit in market economics (e.g. prioritising the need to address local food poverty and exploring the potentials for the Downland to contribute to this.) While these assumptions are obviously of questionable validity, they make room for new narratives that could provide a focus for future mobilisation. Approaches such as this use of (from some perspectives perverse) arguments - e.g. about the potential food productivity of Downland, or of the data that we presented on pesticides, which was critiqued as 'sensationalised' in our second T-Lab workshop - seemed to unsettle current framings more effectively than striving for consensus.

Looking ahead, there have been various re-framings of sustainability challenges at the national level which have had little to do with our work so far, but may interact with it in the future. In particular, the UK's commitment to leave the European Union has sparked a renewed interest in food security and in particular vegetable and fruit growing. This illustrates the potential role of political processes in creating windows of opportunity for reframing debates. While the uncertainty and political upheaval created in the aftermath of the 'Brexit' referendum has been challenging, individual actors and alliances who have engaged in our work have attempted to turn it into an opportunity. The complications of Brexit have also included a recognised need for local authorities to plan for food security (Lang et al. 2018).

\section{Innovation and alternative pathways}

A form of innovation that is of particular relevance to this project is social innovation, which we see as entailing new combinations of resources (people, knowledge, technologies, ways of working) that has an explicit aim to enhance social or environmental outcomes. It might involve new knowledge (e.g. derived from our research project), but does not necessarily. As such, social innovation plays a vital 
role in the production, distribution and consumption (including re-purposing and recycling) of food, and many examples of these feature in the City Food Strategy and Action Plan (BHFP 2018). What's more, through our work we have provided support to a number of social innovations that pre-existed the project, including most notably Seedy Sunday and Brighton and Hove City Food Strategy Action Plan. For instance, we organised a workshop in 2017 on monitoring and evaluation of the City Food Strategy Action Plan, which resulted in the formulation of impact plan; on behalf of Seedy Sunday we undertook a survey in 2017, gave talks in 2017 and 2018, organised an information stand at the annual seed swaps in 2017, 2018 and 2019, and contributed to a seed policy panel in 2018.

While we are not at the stage of prototyping particular new social innovations that have emerged from the project, proposals for these did emerge from the second T-Lab workshop (STEPS Centre 2018). A key outcome of T-Lab 2 was that a policy review involving a participatory democratic process was needed to identify the 'purpose' of the Downland Estate, and that a clear vision and political leadership was required to take it forward to implement a new approach to its management. This could be seen as a bridging innovation. Furthermore, participants articulated the need to map the ecological potentials within the Downland Estate - drawing on and collating existing data on (inter alia) soils, involving soils, morphology, climate, delivery of biodiversity outcomes, natural capital and infrastructure - in order to inform decisions over where opportunities for food production (and other) activities may exist. This is a 'research need' more than a bridging innovation. Nonetheless, it was clear that there were continuing differences of opinion and a general paucity of data and research on the downland surrounding the city and its potential for producing different kinds of food. There was also an ambition, associated with the Biosphere, for the Downland Estate to be a site for innovation in the move towards more sustainable food systems. The proposal for a 'research and innovation hub', which seemed widely welcomed, could be seen as another bridging innovation - one which responded to various aspects of the local context.

\section{Networks, alliances and collective agency}

The T-Lab process brought together various groups, enabling new relationships that have been strengthened over subsequent months (especially with Brighton and Hove Food Partnership). This enabled new, and in some cases stronger, personal and professional relationships to develop between the research community, civil society groups, funders, private sector, media and government actors involved in the problem space. Successive workshops involved progressively greater numbers of people and 'broadened out' (Stirling 2008) to include a more diverse set of actors. This was reflected in a trend towards progressively less generally 'aligned' groups in the co-design workshop, T-Lab 1 workshop and T-Lab 2 workshop - see Figure 5.3.

In connection to this, the group that we convened at the second T-Lab workshop included some who had not engaged with each other before. Nevertheless, 


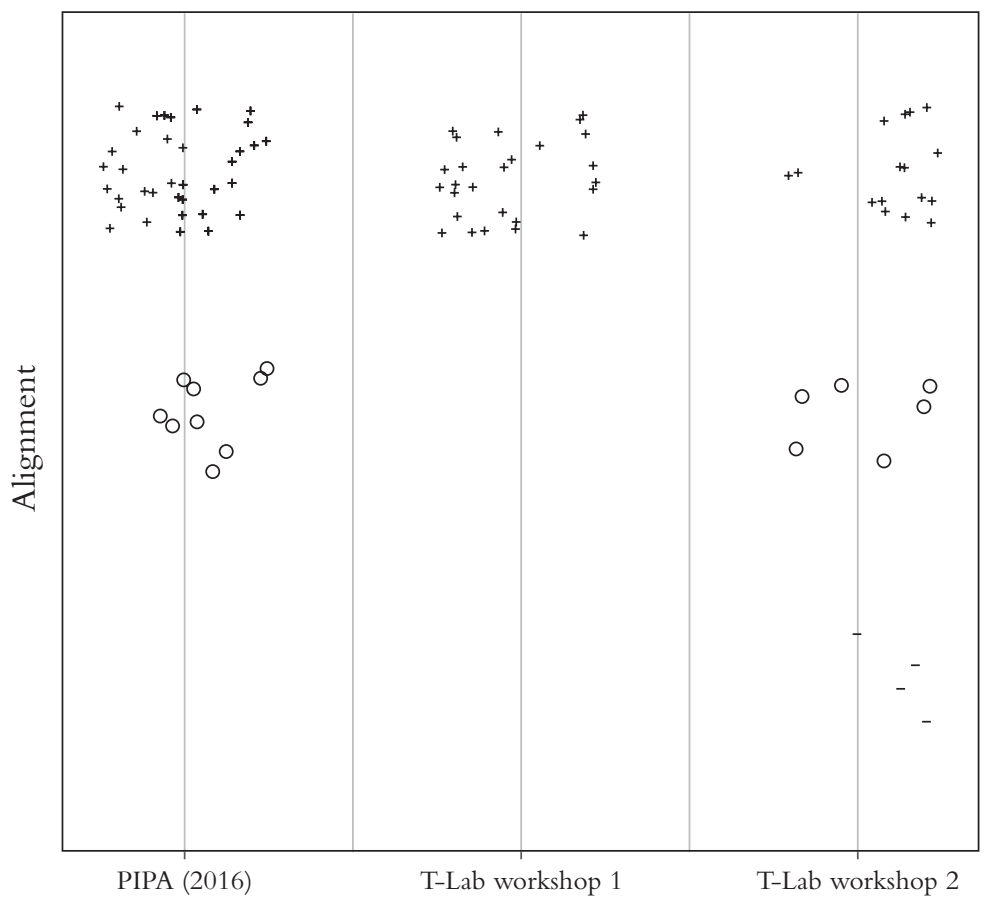

FIGURE 5.3 Number of actors and alignment, as estimated in UK PIPA, T-Lab 1 workshop and T-Lab 2 workshop. Aligned actors are represented by "+”, non-aligned by "-_" and ambivalent by "0".

they were united in a desire to see a sustainable future for the Downland Estate, and - given the very different approaches to production - behaved in a surprisingly collaborative way, even if there were obvious tensions. Although we did not see the spontaneous formation of a self-identifying group, there were calls for something to 'come out of' the event and for the recommendations to be taken forward. Despite the fact that the research team were not able to follow up sufficiently on this at the time, discussions continued, and fed into other work at the University and elsewhere (see Ely and Wach 2018). More recent moves by the local authority (BHCC 2020) to embark upon a consultation process for the Downland Estate take forward some of the ideas discussed in our T-Lab.

\section{Specific insights and contributions from the UK hub}

By the time the project came to a formal conclusion in early 2020, the UK hub work had delivered three specific sets of insights:

1 Alignment and power

In comparison to other hubs (e.g. Argentina), our T-Lab moves from a more aligned, less powerful group towards a less aligned, more powerful 
group. This was partly a strategic choice and partly a result of the momentum that we had developed over the previous years of research.

2 Alignment against as opposed to alignment towards

In terms of 'transformative pathways' and their open-endedness, the T-Lab process (from co-design through to T-Lab 2) illustrated that it is relatively easy to identify groups who are against the dominant pathway. However, they may themselves favour very different transformations. The focus on local food was relatively unquestioned, e.g. but the choice to frame agro-ecological production as a specific solution was not favoured by all. Moreover, while we engaged with numerous actors in a process of negotiating and proposing social innovations for alternative pathways, we completely side-stepped the need to destabilise the conventional (dominant) pathway that was constraining the alternatives that we favoured. In this sense we did not 'challenge power', even though we came together as being opposed to it.

3 Windows of opportunity and wider transformations

The second T-Lab workshop opened up interesting questions about 'windows of opportunity' and how T-Labs can become entangled and embedded in more formal policy processes. It remains to be seen how this takes place (in relation, for instance, to the long-term impacts of the Whole Estate Plan and the City Food Strategy).

This also raised issues regarding the responsibilities of researchers to the knowledge partners with whom they engaged. We unfortunately did not have the resources (in terms of time) to fully engage with these external processes or to be the main driver of the proposals that came out of the T-Lab. But we adopted an approach that saw the T-Lab as co-owned by a number of stakeholders, so that it became embedded into other ongoing processes. This is an interesting take on 'transformative agency' - the researchers acknowledge their own relative lack of agency but intervene in a way that blends in with the ongoing transformation, rather than seeing our intervention as discrete.

\section{References}

Balázs B., Smith, A., Aistara, G. and Bela, G.Y. (2016) Transformative Social Innovation: Transnational Seed Exchange Networks. TRANSIT: EU SSH.2013.3.2-1 Grant agreement no: 613169.

Bangs, D. (2008) A Freedom to Roam Guide to the Brighton Downs from Shoreham to Newhaven and Beeding to Lewes, Farlington: Bishops Printers.

BHCC (2020) Protecting our downland for future generations, https://www.brightonhove.gov.uk/news/2020/protecting-our-downland-future-generations, accessed 18/11/2020.

BHFP (2012) Spade to Spoon: Digging Deeper, A Food Strategy and Action Plan for Brighton and Hove, Brighton and Hove Food Partnership.

BHFP (2018) Brighton and Hove Food Strategy Action Plan 2018-2023, Brighton and Hove Food Partnership, http://bhfood.org.uk/wp-content/uploads/2018/11/Final-FULLWEB-Food-Strategy-Action-Plan.pdf, accessed 11/9/2019. 
Brighton and Lewes Downs Biosphere (2014) http://biospherehere.org.uk/.

Defra (2012) Agricultural and Horticultural Survey 2009 and 2010, Department of Environment, Food and Rural Affairs. London.

Durrant, R. (2014) Civil Society in Sustainability Transitions of Food Systems, DPhil Thesis, University of Sussex.

Durrant, R., Barnes, J., Kern, F. and Mackerron, G. (2018) The acceleration of transitions to urban sustainability: A case study of Brighton and Hove. European Planning Studies, 26(8), pp. 1537-1558.

Ely, A., Van Zwanenberg, P., Wach, E., Obaya, M. and A. Cremaschi (2017) Seeding ideas: Knowledge brokering and recombination for agricultural transformations, https://steps-centre.org/blog/seeding-ideas-knowledge-brokering-recombinationagricultural-transformations/, accessed 11/9/2019.

Ely, A. and Wach, E. (2018) Endings and beginnings: Project-Based Work within Wider Transformations, https://steps-centre.org/blog/endings-and-beginnings-project-basedwork-within-wider-transformations/, accessed 11/9/2019.

Farm Drop (2018) Farm drop blog: "We are sad to announce that the Food Assembly closed its doors in the UK on Friday the 28th of September 2018", https://www. farmdrop.com/blog/foodassembly/?utm_source=foodassembly\&utm_medium= email1, accessed 11/9/2019.

Guy, S. and Inglis, A.S. (1999) 'Tips for trainers: Introducing the "H-form" - A method for monitoring and evaluation, in Gujit, I. and Braden, S. (eds), Learning from Analysis, Participatory Learning and Action Notes, Issue 34, London: International Institute for Environment and Development, pp. 84-87.

IAASTD (2009) Towards Multifunctional Agriculture for Social, Environmental and Economic Sustainability, International Assessment of Agricultural Knowledge, Science and Technology for Development.

Lang, T., Millstone, E., Lewis, T. and McFarlane, G. (2018) Why Local Authorities Should Prepare Food Brexit Plans, London: Food Research Collaboration, https://foodresearch. org.uk/publications/local-authorities-food-brexit/, accessed 11/9/2019.

Laughton, R. (2017) 'A Matter of Scale' A Study of the Productivity, Financial Viability and Multifunctional Benefits of Small Farms (20 ha and less). Land Workers' Alliance and Centre for Agroecology, Coventry University.

Leach, M., Scoones, I. and Stirling, A. (2010) Dynamic Sustainabilities, London: EarthScan.

Olsson, P., Folke, C., Galaz, V., Hahn, T. and Schultz, L. (2007) Enhancing the fit through adaptive co-management: creating and maintaining bridging functions for matching scales in the Kristianstads Vattenrike Biosphere Reserve Sweden. Ecology and Society, 12(1): p. 28. [online] URL: http://www.ecologyandsociety.org/vol12/ iss1/art28/.

Scoones, I., Newell, P. and Leach, M. (eds) (2015) The Politics of Green Transformations, Abingdon: Routledge.

Smith, A. (2006) Green niches in sustainable development: the case of organic food in the United Kingdom. Environment and Planning C: Government and Policy, 24: pp. 439-458.

Smith, A. and Ely, A. (2015) Green Transformations from Below? The Politics of Grassroots Innovation, Chapter 7 in Scoones, I., Newell, P. and Leach, M. (eds), The Politics of Green Transformations, Abingdon: Routledge, pp. 102-118.

Smiths Gore and University of Reading (2006) Downland Initiative Feasibility Study, https://www.brighton-hove.gov.uk/sites/brightonhove.gov.uk/files/SP023\%20 Downland\%20Initiative\%202005.pdf, accessed September 2018.

South Downs National Park Authority (2012) State of the National Park 2012, http:// www.southdowns.gov.uk/about-us/state-of-the-national-park-report-2012, accessed 23/12015. 
STEPS Centre (2017) Evaluation H: Methods "vignette" on the STEPS Centre Methods site https://steps-centre.org/pathways-methods-vignettes/methods-vignettesevaluation-h/, accessed 11/9/2019.

STEPS Centre (2018) The Downland Estate: Contributing to more sustainable food systems for Brighton \& Hove - Report on a workshop held on 12th July 2018, https:// steps-centre.org/wp-content/uploads/2018/09/Downland-Estate-Workshop-July2018-Report.pdf, accessed 11/9/2019.

Stirling, A. (2008) 'Opening up' and 'closing down': Power, participation and pluralism in the social appraisal of technology Science. Technology and Human Values, 33(2): 262-294.

Taylor, R. (2018) Market Linkage Strategies for Local Food Systems: Lessons for Brighton and Hove, https://steps-centre.org/publication/market-linkage-strategies-for-local-foodsystemslessons-for-brighton-hove/, accessed September 2018.

United Kingdom Census (2011) 2011 Census for England, Northern Ireland and Wales, Newport: Office for National Statistics.

Van Zwanenberg, P., Ely, A. and Smith, A. (2011) Regulating Technology: International Harmonisation and Local Realities, London: Earthscan.

Vowles, N. (2016) Concerns raised over council's biggest sell-off of downland in 20 years, The Brighton Argus 9 November.

Wach, E. and Ely, A. (2018) Brighton and Hove's Farmland: Potentials for a More Local and Ecological Food Supply, Brighton: STEPS Centre, https://steps-centre.org/publication/ brighton-hovesfarmland-potentials-for-a-more-local-and-ecological-foodsupply-2/, accessed September 2018.

White, R. and Stirling, A. (2013) Sustaining trajectories towards Sustainability: Dynamics and diversity in UK communal growing activities. Global Environmental Change, 23(5): pp. 838-846.

Willis, G. (2017) Uncertain harvest: Does the loss of farms matter? Campaign to Protect Rural England.

Winter, M., Lobley, M., Chiswell, H., Howe, K., Wilkinson, T. and Wilson, P. (2016) Is there a future for the small family farm in the UK? A report to the Prince's Countryside Fund. 